\title{
Tal Brasil, qual prevenção?
}

\author{
AIDS, sexuality, and gender in a \\ Rio de Janeiro favela
}

\author{
Laura Moutinho \\ Pesquisadora visitante do Instituto de Medicina Social \\ Rua São Francisco Xavier, 524 \\ 20550-012 Rio de Janeiro - RJ Brasil \\ lmoutinho@gbl.com.br
}

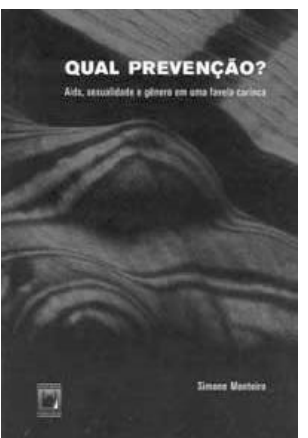

Simone Monteiro Qual prevenção? Aids, sexualidade e gênero em uma favela carioca Rio de Janeiro, Editora Fiocruz, 2002, 148p.
$\mathrm{O}$ livro Qual prevenção? Aids, sexualidade e gênero em uma favela carioca, de Simone Monteiro, vem oportunamente instigar e aguçar nossa reflexão sobre o trabalho de intervenção e os modelos de transformação das práticas dos atores sociais focalizados pelas políticas preventivas. O Brasil vem sendo saudado internacionalmente por seu trabalho na contenção da epidemia de HIV/Aids. Temos visto, nesse sentido, algumas de nossas experiências bem-sucedidas serem exportadas e valorizadas.

No âmbito nacional (mas também internacional), os 'novos' rumos da epidemia estão em questão. De acordo com o último boletim epidemiológico divulgado pela Coordenação Nacional DST/Aids, estamos diante de uma 'pauperização' (que, faz necessário destacar, é medida pela escolaridade) e 'heterossexualização' da epidemia. Neste quadro, aparecem com destaque as jovens mulheres, entre 13 e 19 anos - faixa etária que registrou pela primeira vez um número maior de casos entre mulheres que entre homens. Tais dados evidenciam rumos que colocam desafios às ações de intervenção que vêm sendo realizadas no país, desafios estes enfrentados por Simone Monteiro com um arsenal interdisciplinar que a autora prova ser absolutamente necessário à construção de políticas públicas amplas e coordenadas, que considerem a forma como a sexualidade é vivida por pessoas de classe, gênero e 'cor/raça' diferenciados.

Caminhando com segurança por um território complexo, Simone Monteiro nos conduz, em cinco ágeis capítulos, pelos labirintos de um campo-limite das políticas preventivas. Nesse sentido, a epidemia da Aids configura tensões para onde convergem questões relativas à saúde pública, mas igualmente aos direitos humanos, consubstanciados nos dilemas autonomia/responsabilidade, universal/particular, direitos sexuais/reprodutivos, entre outros. Estes, por sua vez, iluminam e interpelam temas clássicos da antropologia como individualismo e holismo, tradicional e moderno, o 'nós' e o 'outro', diante de fronteiras de poder e simbólicas marcadas, mas em processo de transformação e mudança.

$\mathrm{O}$ rico e instigante quadro de referências e reflexões aberto no livro tem, entretanto, um interlocutor privilegiado: a saúde pública. Este é um aspecto importante, pois a organização da análise — inicialmente tese de doutorado da autora, agora disponível a um público mais amplo — está estruturada com um olho no padre (a saúde pública, sob o enfoque epidemológico, centrado na informação sobre os riscos, na vulnerabilidade e na responsabilidade individual, calcados em teorias cognitivo-comportamentais) 
e outro na missa (a necessidade de incorporação de instrumentos diversos para interpretação e enfrentamento da epidemia).

$\mathrm{Na}$ introdução e nos dois primeiros capítulos do livro, o ponto e o problema são situados a partir de uma análise competente (e crítica) dos modelos que orientaram os primeiros anos de ação contra a epidemia, seguidos de um vasto conjunto interdisciplinar de discussões sobre Aids, juventude, diversidade cultural e pluralidade, representações e práticas culturais vistos sob uma perspectiva socioantroplógica.

As inquietações de Simone Monteiro — originárias da experiência com projetos de pesquisa e programas relativos ao desenvolvimento e à avaliação de ações na área de prevenção à Aids - a (e nos) conduzem para as trajetórias de gênero e sexualidade, em sua interface com as representações e práticas relativas à proteção da saúde (e da vida) experimentadas por rapazes e moças que habitam a favela de Vigário Geral, no subúrbio do Rio de Janeiro.

Ao circunscrever os valores e representações culturais do universo estudado como predominantemente holista, tradicional e hierárquico, a autora inscreve sua análise em uma das matrizes clássicas do pensamento antropológico brasileiro. Sua contribuição particular se evidencia na forma como qualifica e contextualiza este 'tradicional' — que, é importante ressaltar, não aparece localizado na chave do atraso. Qualificar e não reificar essas diferenças é um desafio. O livro de Simone Monteiro nos auxilia nessa tarefa de fundamental importância, fomentando o debate com dados, reflexões e interlocuções diversas. Adquire um viés particularmente interessante e rico na interface com as questões caras à saúde pública.

Vigário Geral é uma favela bem conhecida daqueles que acompanham (e creio que também dos que não acompanham) os noticiários brasileiros. A notoriedade chegou por um trágico evento, a 'chacina de Vigário Geral', ocorrida em 1993, quando 21 moradores da favela foram assassinados por policiais militares. Simone Monteiro chegou à 'comunidade' três anos depois - mesmo período em que a polícia começou a ocupar a favela —, mas as marcas da chacina e da violência na vida dos moradores aparecem com clareza em seu trabalho.

Esse é um aspecto importante, pois os jovens entrevistados (18 mulheres e 14 homens entre 14 e 19 anos) foram socializados em meio a um território de disputas, com um contato mais ou menos direto com a violência e o tráfico de drogas. Este, entretanto, costura o idioma de gênero e sexualidade local, assim como as expectativas em relação ao futuro e a própria lógica de proteção e os cuidados com a saúde.

No capítulo 3, momento em que começamos a conhecer o trabalho de campo realizado pela autora, vemos o drama da falta de perspectiva futura pela contundente fala de um rapaz que questiona o lugar do ensino formal (valorizado na região) como via de ascensão social: seus conhecimentos adquiridos (estudou até a 5ํㅗㅅ série) são utilizados no trabalho ilegal que realiza junto ao tráfico de drogas. Nas suas palavras, "Cozinheiro, tão pedindo $2^{\circ}$ grau. ... Ué, pra que precisa de $2^{\circ}$ grau? Não dá para entender, nego com $2^{\circ}$ grau varrendo rua ..." (p. 66). Trata-se de uma visão particular e, como indica Simone Monteiro, não deve ser generalizada.

É significativa também a narrativa de um rapaz de 18 anos que afirma ser respeitado entre os colegas por ter 'escolaridade'. Mas quando 
acompanhamos com a autora a trajetória de alguns moradores de Vigário Geral, observamos que a primeira fala registrar uma percepção que não deve ser negligenciada, pois aponta para o lugar e os limites do ensino formal para aquisição de bens, prestígio, status e melhoria de vida.

Nesse universo, a escola aparece como um território em disputa por duas ordens: a legal e a ilegal. De fato, como espaço de legalidade, da aquisição de um saber formal, da divulgação de orientações relativas à sexualidade, à saúde e a própria vida, a escola não parece ter um lugar efetivo nesse universo. Como é registrado pela autora, um uso instrumental do ensino, ou seja, a aquisição de um saber elementar, porém suficiente para atuar fora do mercado de trabalho formal, coloca em xeque a escola, tanto como instituição responsável pelo 'acesso à cultura letrada', como, igualmente, pela transmissão de uma ordem legal. No tipo de cultura viril predominante em áreas pobres, onde o tráfico atua, há que considerar a pouca capacidade de a escola fornecer um modelo masculino (e também feminino) mais competitivo, digamos, dentro da lógica de disputa local.

Contribui para isso a fluidez da fronteira entre essas ordens: o sistema de coleta de lixo foi até um certo momento realizado pelos traficantes, que, embora 'bandidos', também são vistos como 'integrantes da comunidade', 'protetores locais', 'benfeitores', "(aqueles que) trazem lazer e festas". O policial, 'elemento externo', protege pouco e desrespeita muito: 'ameaça', 'agride', 'limita o lazer e a liberdade'. Para a autora, trata-se de uma lógica que ganha inteligibilidade a partir das categorias sociológicas de 'casa' e 'rua', analisadas por Roberto DaMatta. A primeira simboliza o universo da proteção, da segurança e da família; a segunda, a indiferença, o individualismo, o anonimato e o perigo.

Tendo em vista o terreno polêmico em que o estudo se circunscreve, algumas questões provocam o leitor para o debate. O perfil tradicional e hierárquico de gênero e sexualidade identificado por Simone Monteiro levanta, por exemplo, aspectos interessantes quando contrastado com as condições objetivas de vida desses jovens moradores de Vigário Geral. Em certos momentos da análise, deparamos com narrativas que de fato os aproximam da perspectiva registrada na literatura antropológica como holista e hierárquica. Entretanto, se em diversos momentos as condições (precárias) de vida parecem coadunar com a perspectiva simbólica que opera com a tradicional hierarquia entre os gêneros, em outros, diferentemente do que aponta a autora, são as condições materiais de vida que parecem não possibilitar um arranjo de gênero mais variado e/ou construído sob bases assimétricas menos tradicionais.

As meninas, por exemplo, por vezes são movidas por conflitos familiares, desejam sair da casa dos pais e somente encontraram no tráfico de drogas algum espaço de mobilidade. Nesse sentido, o retorno à casa (comum, diante do alto risco da atividade e do ethos viril que caracteriza o tráfico) e o movimento em direção à constituição de sua própria família guardam menos relação com o perfil tradicional de gênero identificado pela autora, referindo-se antes à falta de perspectiva e de recursos disponíveis - é significativo que, dentre os anseios expressos pelas moças, encontrem-se carreiras de alto status, como informática, medicina e direito. Diante deste quadro, o homem se mantém (também precocemente) no lugar de provedor: 
deve 'pegar responsabilidade'. Em resumo, é premido a entrar no mercado de trabalho e sustentar a família.

As narrativas sobre sexualidade apontam para um repertório sexual complexo e interessante, que sugerem a subordinação do sistema de sexualidade ao de gênero. O maior controle da conduta feminina, a própria valorização da virgindade, entre outros elementos opostos e complementares à conduta masculina, evidenciam roteiros sexuais diferenciados e ordenados pela assimetria entre os gêneros. Esta estrutura revela, entretanto, alguns arranjos e percepções interessantes dos entrevistados no tocante à clareza quanto à conduta machista, ou mesmo alguma negociação com relação a certas práticas sexuais.

Um argumento importante trazido pela autora refere-se à forma como o poder do consumo se inscreve nesse universo como elemento de modernização, modificando as redes de reciprocidade locais e alterando a relação de valor antes alocada no trabalho. Trata-se de uma pista que merece ser explorada por outros estudos e em localidades, em especial com relação à repercussão do assédio da ideologia do consumo às ideologias de gênero e sexualidade.

Ao comparar algumas das manobras preventivas identificadas por Simone Monteiro entre os jovens de Vigário Geral com outros trabalhos sobre contextos culturais e segmentos sociais diversos - dos quais a autora lança mão -, vemos que 'confiança', 'vínculo amoroso', 'proximidade' e 'distância' são cálculos presentes nas relações afetivo-sexuais de um modo geral. Assim, não são exclusivas desse segmento - embora haja as especificidades vivenciadas no contexto.

Um dos pontos da análise nos leva a pensar que tudo isso indique talvez que, além de nos voltarmos para as lógicas sociais e simbó-licas que funcionam como filtro diferenciado na escuta das informações veiculadas, devemos concomitantemente inquirir o indivíduo em foco pelas políticas preventivas. Ao término da leitura, sai-se com a sensação de que este indivíduo, com o alto grau de racionalidade que o caracteriza, não está em lugar algum: nem nos segmentos médios/altos, e tampouco nos populares. Em outras palavras, a análise empreendida por Simone Monteiro nos permite evocar um dos ensinamentos clássicos do antropó-logo Claude Lévi-Strauss (1985, p. 54), presente em Raça e história: “... o homem não realiza a sua natureza numa humanidade abstrata, mas nas culturas tradicionais ..." .

Ao voltarmos nosso olhar para esses jovens moradores de Vigário Geral, considerando as lógicas sociais e culturais que orientam suas práticas cotidianas, vemos como o estudo de Simone Monteiro contribui para a compreensão e o alargamento deste momento-limite das políticas preventivas. Um maior controle da epidemia depende, como mostra a autora, da melhoria das condições objetivas de vida (como educação, saúde, moradia, emprego, poder aquisitivo), combinada com o conhecimento em profundidade das lógicas culturais e simbólicas inscritas em localidades específicas e dos cálculos preventivos operados nas relações afetivo-sexuais. 


\section{REFERÊNCIAS BIBLIOGRÁFICAS}

DaMatta, Roberto

1991

Lévi-Strauss, Claude 1985
A casa e a Rua.

Rio de Janeiro, Guanabara Koogan.

Raça e bistória. $2^{\mathrm{a}}$ ed.

São Paulo, Abril Cultural (Coleção Os Pensadores).

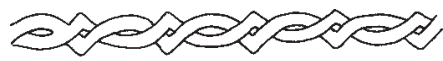

